\title{
VESTIBULAR BIBLIOGRAPHY
}

Tri-chloroacetic acid: A cause of vulvar vestibulitis [9] Nunns D.;Mandal D. Acta Dermato-Venereologica 76/4 334

The contribution of the vertical semicircular canals to high-velocity horizontal vestibulo-ocular reflex (VOR) in normal subjects and patients with unilateral vestibular nerve section Tusa R.J.;Grant M.P.;Buettner U.W.;Herdman S.J.;Zee D.S. Acta Oto-Laryngologica 1 16/4 507-512

Contributions of single semicircular canals to caloric nystagmus as revealed by canal plugging in Rhesus monkeys Bohmer A.;Straumann D.;Suzuki J.-I.;Hess B.J.M.;Henn V. Acta Oto-Laryngologica $116 / 4$ 513-520

Effect of glycerol on electrochemical composition of endolymph and perilymph in the rat Morrison G.A.J.;Teixeira M.;Sterkers O.;Amiel C.;Ferrary E.Acta Oto-Laryngologica 116/4 546-551

Distribution of amyloid bodies in the aged human vestibulocochlear nerve Fujii M.;Goto N.;Okada A.;Kida A.;Kikuchi K. Acta Oto-Laryngologica 116/4 566-571

Inhibitory effect of erythromycin on ion transport by stria vascularis and vestibular dark cells Liu J.;Marcus D.C.;Kobayashi T. Acta Oto-Laryngologica 116/4 572-575

Sensori-motor function, gait patterns and falls in community-dwelling women Lord S.R.;Lloyd D.G.;Li S.K. Age and Ageing 25/4 292-299

Phenytoin-induced toxic epidermal necrolysis: A case report Creamer J.D.;Whittaker S.J.;KerrMuir M.;Smith N.P. Clinical and Experimental Dermatology 21/2 116-120

Recognition of direction of uniform and accelerated visual motion and EEG alpha wave phases Shevelev I.A.;Kamenkovich V.M.;Kostelianetz N.B.;Sharaev G.A. FEBS Letters 392/2 169-174

Activity of hippocampal pyramidal neurons during trace eyeblink conditioning Weiss C.;KronforstCollins M.A.;Disterhoft J.F. Hippocampus 6/2 192-209

Effects of single and multiple doses of dexnafenodone, imipramine and placebo on sleep of young healthy volunteers Schulz H.;Legler U.;Jobert M.;Greger G. Human Psychopharmacology 11/321 1-215

Development of vestibular function: Biochemical, morphological and electronystagmographical assessment in the rat Meza G.;Acuna D.;Gutierrez A.;Merchan J.M.;Rueda J. International Journal of Developmental Neuroscience 14/4 507-513

Development of vestibular and auditory function: Effects of hypothyroidism and thyroxine replacement therapy on nystagmus and auditory evoked potentials in the pigmented rat Meza G.;Acuna D.;Escobar C. International Journal of Developmental Neuroscience 14/4 515-522

Study of labyrinthine function in children using the caloric test: Our results Melagrana A.;DAgostino'R.;Pasquale G.;Taborelli G. International Journal of Pediatric Otorhinolaryngology 37/1 1-8

The magnitude of the fixation offset effect with endogenously and exogenously controlled saccades Forbes K.;Klein R.M. Journal of Cognitive Neuroscience 8/4 344-352

Transneuronal pathways to the vestibulocerebellum Kaufman G.D.;Mustari M.J.;Miselis R.R.;Perachio A.A. Journal of Comparative Neurology 370/4 501-523 
Anticipatory saccades in sequential procedural learning in monkeys Miyashita K.;Miya Kato Rand;Miyachi S.;Hikosaka O. Journal of Neurophysiology 76/2 1361-1365

Neurons in the supplementary eye field of rhesus monkeys code visual targets and saccadic eye movements in an oculocentric coordinate system Russo G.S.;Bruce C.J. Journal of Neurophysiology 76/2 825-848

Activity of visuomotor burst neurons in the superior colliculus accompanying express saccades Edelman J.A.;Keller E.L. Journal of Neurophysiology 76/2 908-926

Combined eye-head gaze shifts produced by electrical stimulation of the superior colliculus in rhesus monkeys Freedman E.G.;Stanford T.R.;Sparks D.L. Journal of Neurophysiology 76/2 927-952

Ipsapirone, a 5-HT(1A) agonist, suppresses REM sleep equally in unmedicated depressed patients and normal controls Gillin J.C.;Sohn J.-W.;Stahl S.M.;Lardon M.;Kelsoe J.;Rapaport M.;Ruiz C.;Golshan S. Neuropsychopharmacology 15/2 109-115

Violation of superposition by the vestibulo-ocular reflex of the goldfish Dow E.R.;Anastasio T.J. NeuroReport $7 / 7$ 1305-1309

Vestibular influences on hypoglossal nerve activity in the cat Rossiter C.D.;Yates B.J. Neuroscience Letters 211/1 25-28

The caudo ventral pontine tegmentum is involved in the generation of high velocity eye saccades in bursts during paradoxical sleep in the cat Vanni-Mercier G.;Debilly G.;Lin J.S.;Pelisson D. Neuroscience Letters 213/2 127-131

Chloroquine specifically impairs Merkel cell mechanoreceptor function in isolated rat sinus hairsSenok S.S.;Halata Z.;Baumann K.I. Neuroscience Letters 214/2-3 167-170

Postural responses to vibration of neck muscles in patients with unilateral vestibular lesions Popov K.;Lekhel H.;Bronstein A.;Gresty M. Neuroscience Letters 214/2-3 202-204

Cross axis vestibulo-ocular reflex induced by pursuit training in alert monkeys Fukushima K.;Fukushima J.;Chin S.;Tsunekawa H.;Kaneko C.R.S. Neuroscience Research 25/3 255-265

Adaptive changes in human smooth pursuit eye movement Fukushima K.;Tanaka M.;Suzuki Y.;Fukushima J.;Yoshida T. Neuroscience Research 25/4 391-398

Vestibular compensation in aged rats with unilateral labyrinthectomy treated with dopaminergic drugs Drago F.;Nardo L.;Rampello L.;Raffaele R. Pharmacological Research 33/2 135-140

The extraordinarily rapid disappearance of entoptic images Coppola D.;Purves D. Proceedings of the National Academy of Sciences of the United States of America 93/15 8001-8004

Coevolution of the mammalian middle ear and neocortex Rowe T. Science 273/5275651-654

Temporal impulse response functions for luminance and colour during saccades Burr D.C.;Morrone M.C. Vision Research 36/14 2069-2078

Adaptive changes in saccade amplitude: Oculocentric or orbitocentric mapping? Albano J.E. Vision Research 36/14 2087-2098

Using eye saccades to assess the selectivity of search movements Zelinsky G.J. Vision Research 36/14 $2177-2187$

Two contributions to motion induction: A preattentive effect and facilitation due to attentional capture Von Grunau M.;Dube S.;Kwas M. Vision Research 36/162447-2457

Disconjugate adaptation of the vertical oculomotor system Kapoula Z.;Eggert T.;Bucci M.P. Vision Research 36/17 2735-2745 
Erratum: Masking of the achromatic system: Implications for saccadic suppression (Vision Research (1996) 36 (1551-1559)) Schwartz S.H.;Godwin L.D. Vision Research 36/17 2795

Pattern of ocular dominance columns in human striate cortex in strabismic amblyopia Horton J.C.;Hocking D.R. Visual Neuroscience 13/4 787-795 